\title{
BMJ Open How many patients are eligible for disease-modifying treatment in Alzheimer's disease? A French national observational study over 5 years
}

\author{
Stéphane Epelbaum, ${ }^{\oplus 1}$ Claire Paquet, ${ }^{2}$ Jacques Hugon,, ${ }^{3,4}$ Julien Dumurgier, ${ }^{4,5}$ \\ David Wallon, ${ }^{6}$ Didier Hannequin, ${ }^{7}$ Thérèse Jonveaux, ${ }^{8}$ Annick Besozzi, ${ }^{8}$ \\ Stéphane Pouponneau, ${ }^{9}$ Caroline Hommet, ${ }^{9}$ Frederic Blanc, ${ }^{10}$ Laetitia Berly, ${ }^{11}$ \\ Adrien Julian, ${ }^{12}$ Marc Paccalin, ${ }^{13}$ Florence Pasquier, ${ }^{14}$ Julie Bellet, ${ }^{15}$ \\ Claire Boutoleau-Bretonniere, ${ }^{16}$ Thiphaine Charriau, ${ }^{17}$ Olivier Rouaud, ${ }^{18}$ \\ Olivier Madec, ${ }^{18}$ Aurélie Mouton, ${ }^{19}$ Renaud David, ${ }^{20}$ Samir Bekadar, ${ }^{21}$ \\ Roxane Fabre, ${ }^{19}$ Emmanuelle Liegey, ${ }^{22}$ Walter Deberdt, ${ }^{23}$ Philippe Robert, ${ }^{19}$ \\ Bruno Dubois ${ }^{24}$
}

To cite: Epelbaum S, Paquet C, Hugon J, et al. How many patients are eligible for disease-modifying treatment in Alzheimer's disease? A French national observational study over 5 years. BMJ Open 2019;9:e029663. doi:10.1136/ bmjopen-2019-029663

- Prepublication history for this paper is available online To view these files, please visit the journal online (http://dx.doi org/10.1136/bmjopen-2019029663).

Received 11 February 2019 Revised 18 April 2019 Accepted 29 May 2019
Check for updates

(C) Author(s) (or their employer(s)) 2019. Re-use permitted under CC BY-NC. No commercial re-use. See rights and permissions. Published by BMJ.

For numbered affiliations see end of article.

Correspondence to Dr Stéphane Epelbaum; stephane.epelbaum@aphp.fr

\section{ABSTRACT}

Objective We aimed to study the epidemiology of the prodromal and mild stages of Alzheimer's disease (AD) patients who are eligible for clinical trials with diseasemodifying therapies.

Settings We analysed two large complementary databases to study the incidence and characteristics of this population on a nationwide scope in France from 2014 to 2018. The National Alzheimer Database contains data from 357 memory centres and 90 private neurologists. Data from 2014 to 2018 have been analysed.

Participants Patients, 50-85 years old, diagnosed with AD who had an Mini-Mental State Exam (MMSE) score of $\geq 20$ were included. We excluded patients with mixed and non-AD neurocognitive disorders.

Primary outcome measure Descriptive statistics of the population of interest was the primary measure.

Results In the National Alzheimer Database, 550198 patients were assessed. Among them, 72174 (13.1\%) were diagnosed with $A D$ and had an MMSE $\geq 20$. Using corrections for specificity of clinical diagnosis of $A D$, we estimated that about $50000(9.1 \%)$ had a prodromal or mild AD. In the combined electronic clinical records database of 11 French expert memory centres, a diagnosis of prodromal or mild $A D$, certified by the use of cerebrospinal fluid AD biomarkers, could be established in $195(1.3 \%)$ out of 14596 patients.

Conclusions $A D$ was not frequently diagnosed at a prodromal or mild dementia stage in France in 2014 to 2018. Diagnosis rarely relied on a pathophysiological marker even in expert memory centres. National databases will be valuable to monitor early stage $A D$ diagnosis efficacy in memory centres when a diseasemodifying treatment becomes available.

\section{BACKGROUND}

Alzheimer's disease (AD) affects over 1 million people in France, 35 million
Strengths and limitations of this study

- Use of two large, multicentric, national databases representative of the French healthcare network on Alzheimer's disease.

- Absence of data to explain the low rate of early Alzheimer's disease diagnosis in the French national Alzheimer database (BNA).

- A retrospective design for the electronic record file database that does not allow for definitive epidemiological conclusions.

individuals worldwide, and is one of the major challenges of this century for the scientific community. ${ }^{1}$ Most trials aiming to hinder its progression ${ }^{2}$ are now conducted in its mild or even prodromal stage. ${ }^{3-5}$ Today, an early and reliable diagnosis can be made in expert centres, which have the necessary resources for core $\mathrm{AD}$ biomarker analyses, for example, cerebrospinal fluid (CSF) analysis. ${ }^{6}$

Although some of these trials have already shown a lack of treatment efficacy even at the mild AD stage, ${ }^{78}$ some undergoing trials are testing treatments which showed encouraging phase $\mathrm{Ib}$ and II results. ${ }^{9} 10$

In France, the evaluation of patients in expert memory clinics is standardised with the use of the same neuropsychological tests and AD CSF biomarkers (Aß42, tau and phosphorylated tau) sampling in clinical practice.

Also, since 2009, a national medical database has been running, the 'Banque Nationale Alzheimer (BNA)' (The National Alzheimer's Bank), which was set up as part 
of the national Alzheimer's Plan (2008-2012) and has already been thoroughly described. ${ }^{11}$

Our aim was to evaluate the incidence of early $\mathrm{AD}$ patients who would be eligible for a disease-modifying drug trial in a French multicentric retrospective study in France between 2014 and 2018.

\section{METHODS}

\section{Participants}

Two distinct databases were analysed: the first was constituted for the purpose of this study as a collaborative effort from 11 expert memory centres in 2014 when the results from the Expedition III trial testing Solanezumab had not yet been disclosed. The second database is the ongoing BNA in which data are available from 2014 to 2018.

\section{First database: electronic clinical records database}

A retrospective multicentric study based on a database from 11 'Centres de mémoire, de recherche et de ressources' (Memory, Research and Resource Centres), CMRR. In alphabetical order: Dijon, Lille, Nantes, Nancy, Nice, Paris-Lariboisière, Paris-Pitié-Salpêtrière, Poitiers, Rouen, Strasbourg, Tours) volunteered to participate in this study. Each of these centres kept their patient files in local electronic clinical records (ECR). The criteria of selected patients who would be eligible for a disease-modifying drug trial were derived from that of the Expedition III clinical trial (Clinicaltrials.org: NCT02760602) and are in line with the International Working Group (IWG) guidelines. ${ }^{45}$ The selected criteria, demographic (age, gender, education level, distance to CMRR, caregiver, referral) and medical data (conventional anti-AD treatment, participation in a clinical trial) were recorded in this population. Importantly, patients diagnosed with mixed dementia were not included in our study, once again to mirror the inclusion criteria of the disease-modifying drugs trials. More specifically, the inclusion criteria used in this study were as follows:

- Age between 50 and 85 years old.

- AD diagnosis based on the IWG-2 criteria operationalised as a Free and Cued Selective Reminding test (FCSRT) total score $<42$ AND a CSF phosphorylated tau/Aß42 ratio above 0.11 .

- A mild or prodromal (mild cognitive impairment (MCI) ) stage of the disease defined by an mini-mental state exam (MMSE) score $>20$ also referred to as 'early $\mathrm{AD}$ '.

Exclusion criteria were as follows:

- The presence of significant vascular lesions on MRI defined as Fazekas and Schmidt leukopathy stage 3 or the presence of at least one lacunar or territorial infarct or supracentimetric brain haemorrhagic sequelae.

- The presence of another disease that could better explain the symptoms (eg, dementia with Lewy bodies and fronto-temporal dementia).
- Patient opposition to the use of his/her anonymised clinical data for research purposes according to the French legislation.

\section{Second database: National Alzheimer database (BNA)}

In order to broaden the analysis to a national level and extend it over time, the BNA was used to assess the total number of clinically diagnosed $\mathrm{AD}$ and MCI (divided into amnestic (aMCI) and non-amnestic MCI (naMCI) based on clinical assessment) individuals in 2014 and 2015 who had an MMSE score $\geq 20$. From 2016 onwards, the BNA structure changed to integrate the Diagnostic and Statistical Manual fifth edition nomenclature ${ }^{12}$ and to require stating whether CSF biomarkers or genetic features were used to ascertain $\mathrm{AD}$ diagnosis or not. These results were stratified by the type of clinic (primary memory clinic, CMRR or private neuro specialist) in which the patients had been evaluated. Among the data systematically collected, we assessed the Mini Mental State Evaluation (MMSE) score ${ }^{13}$ and the diagnosis according to the International Classification of Diseases, 10th Revision. ${ }^{14} \mathrm{AD}^{15}$ and MCI, subcategorised as aMCI or naMCI, ${ }^{3}{ }^{16}$ are included among the diagnostic categories in the BNA. Both items (MMSE and diagnosis) are recorded each time a patient consults in one of the 357 participating memory clinics (representing $83.6 \%$ of all memory clinics in France) and 90 private neurology specialists. These clinics are divided into two categories: primary memory clinics (328/357) and expert memory centres (CMRR 29/357). Clinical diagnosis of $\mathrm{AD}$ and $\mathrm{MCI}$ was used to estimate the number of 'true' $\mathrm{AD}$ cases, taking into account the relative specificity for pathophysiologically confirmed $\mathrm{AD}$ of the different clinically determined diagnostic categories, that is, $70 \%$ for the specificity of the clinical $\mathrm{AD}^{17} 18$ and $50 \%$ for the MCI syndrome. ${ }^{19}$ BNA was also used to assess by comparing patient characteristics between the 11 CMRR cohort and the 18 that did not participate in the study.

\section{Ethics}

Both the ECR and BNA databases and their utilisation for the purpose of this study were approved by Paris VI Institutional Review Board and the Commission Nationale de l'Informatique et des Libertés ('National commission for informatics and liberty') responsible in France for data protection and use concerning human identity and human rights. French Legislation allows the use of anonymised clinical data if patients did not specifically object to it during consultation. Hence, every patient included in this study did not oppose to the use of his/her clinical data. However, no written consent was obtained either for the ECR or for the BNA database.

\section{Patient and public involvement}

Patients were not specifically involved in this study. The BNA is publicly disseminated (http://www.innovationalzheimer.fr/bna-fr/). 


\section{Neuropsychological tests}

The MMSE ${ }^{13}$ and the FCSRT ${ }^{20}$ were collected in the ECR database. The FCSRT is a well-validated tool to diagnose $\mathrm{AD}$, even at its prodromal stage. ${ }^{21-25}$ It is recommended in the diagnosis of $\mathrm{AD}$ by the IWG guidelines. ${ }^{45}$ This test is now implemented to screen patients in disease-modifying drug trials (eg, Clinicaltrials.org: NCT02760602). In our study, we included patients with a free recall score $<20$ or a total recall score $<42 .{ }^{21}$ The mild or prodromal stages were ascertained by an MMSE score $>20$. In the BNA, only the MMSE was available.

\section{Cerebrospinal fluid biomarkers of $A D$}

CSF was acquired following standard procedures. The CSF was obtained by LP between the L3/L4 or L4/L5 intervertebral space, using a 22-gauge atraumatic needle. Five hundred microlitres of CSF were used to perform standardised commercially available INNOTEST sandwich ELISA according to the manufacturer's instructions (Fujirebio Europe NV, formerly Innogenetics NV). A CSF profile of the Alzheimer's type was defined by a phosphorylated tau/Aß42 ratio $>0.11 .{ }^{6}{ }^{26} \mathrm{CSF}$ biomarkers results were available in the ECR database but not in the BNA.

\section{Statistical analysis}

First, we studied the descriptive statistics of the population of interest derived from the analysis performed in the 11 CMRR. To assess the external validity of our results, we compared the BNA data from these 11 CMRR to those of the remaining 18 CMRR.

To compare sociodemographic and medical characteristics between the 11 CMRR that volunteered to participate in this study and the other 18 CMRR (using data that were available for these CMRR in the BNA), we performed Student's t-tests for quantitative variables describing means and $\mathrm{SD}$ and $\mathrm{X}^{2}$ tests for qualitative variables after an assessment of the Gaussian distribution of the continuous variables using the Kolmogorov-Smirnov test. All reported $p$ values are two-sided. Statistical analyses and description of the cohort characteristics were performed with SAS software V.4.1 (SAS, Cary, North Carolina, USA).

\section{RESULTS}

In 2014, 14596 patients had a cognitive evaluation in one of the 11 participating CMRRs. Among these, 1209 $(8.3 \%)$ underwent a lumbar puncture with an analysis of AD CSF biomarkers. Among them, 195 (16.1\%) had an 'early AD' diagnosis per our chosen criteria, 287 (23.7 $\%)$ had a diagnosis of AD with an MMSE <20; 64 (5.3\%) had a diagnosis of AD with an MMSE $>20$ but an FCSRT with subscores over our chosen thresholds; 365 (30.2\%) had a mixed dementia profile (AD and vascular lesions 237 (65\%); $\mathrm{AD}$ and suspected Lewy body dementia 84 (23\%); AD and other $44(12 \%))$ and finally 298 (24.7\%) had another diagnosis (not AD). Among the 195 patients (16.1\% of patients who underwent a CSF examination, $1.3 \%$ of all patients) who had a diagnosis of early $\mathrm{AD}$ according to the IWG-2 criteria, $133(68.2 \%)$ had a mild AD dementia and $62(31.8 \%)$ had prodromal AD. The proportions of CSF examinations and of mild or prodromal $\mathrm{AD}$ patients among patients who performed a neuropsychological evaluation in the CMRR the same year were not statistically different from one CMRR to the next as presented in figure 1 . The characteristics of these early $\mathrm{AD}$ patients are presented in table 1 .

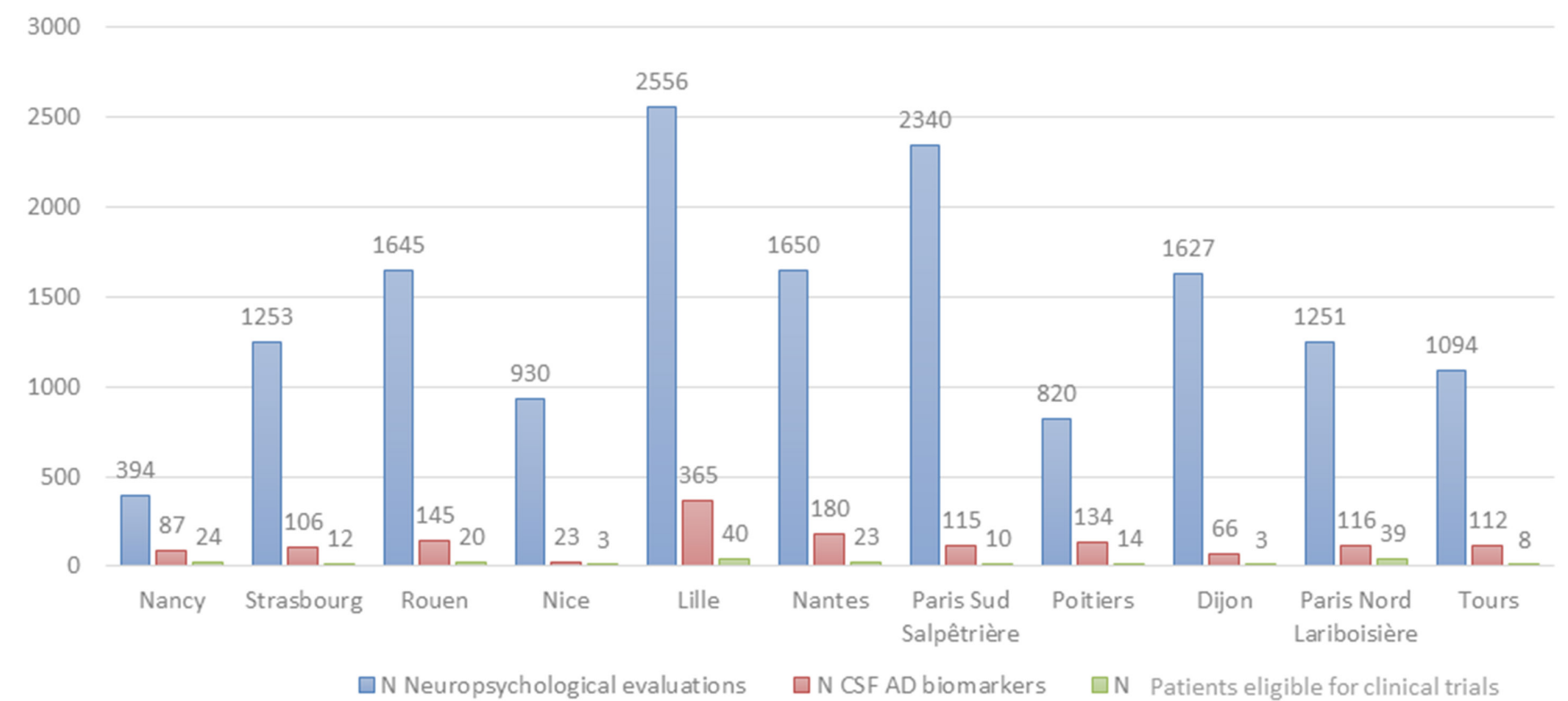

Figure 1 Incidence of prodromal and mild IWG-2 Alzheimer's disease patients in 2014 in the electronic clinical files of 11 CMRRs. CMRRs, Centres de mémoire, de recherche et de ressources (Centres for Research and Resources on Memory); IWG, International Working Group. 
Table 1 Description of the 195 patients from the electronic clinical files database

\begin{tabular}{|c|c|}
\hline & Mean (SD) or $\mathbf{N}(\%)$ \\
\hline Age & $70.8(0.6)$ \\
\hline Gender-female & $108(55.1)$ \\
\hline Educational level (years of education) & $10.7(0.4)$ \\
\hline Distance from CMRR (km) & $40.1(6.7)$ \\
\hline MMSE & $24.7(0.2)$ \\
\hline FCSRT-FR & $10.8(0.4)$ \\
\hline FCSRT-TR & $29.1(1.8)$ \\
\hline$A ß 1-42(p g / m L)$ & $527.7(11.6)$ \\
\hline tau (pg/mL) & $672.5(23.6)$ \\
\hline Phosphorylated tau (pg/mL) & $110.9(7.4)$ \\
\hline Phosphorylated tau/Aß1-42 ratio & $0.21(0.01)$ \\
\hline \multicolumn{2}{|l|}{ Caregiver $(n=74)$} \\
\hline Spouse & $59(79.7)$ \\
\hline Children & $10(13.5)$ \\
\hline Other & $5(6.8)$ \\
\hline \multicolumn{2}{|l|}{ Addressed by $(n=74)$} \\
\hline Family & $8(13.3)$ \\
\hline General practitioner & $29(48.3)$ \\
\hline Neurologist & $17(28.3)$ \\
\hline Psychiatrist & $4(6.7)$ \\
\hline Other & $2(3.4)$ \\
\hline \multicolumn{2}{|l|}{ Anti-AD drug $(n=60)$} \\
\hline 0 & $12(20)$ \\
\hline DONEPEZIL $5 \mathrm{mg}$ & $2(3.3)$ \\
\hline DONEPEZIL $10 \mathrm{mg}$ & $16(26.7)$ \\
\hline GALANTAMINE $16 \mathrm{mg}$ LP & $3(5)$ \\
\hline GALANTAMINE 24 mg LP & $6(10)$ \\
\hline RIVASTIGMINE $12 \mathrm{mg}$ & $2(3.3)$ \\
\hline RIVASTIGMINE $4.6 \mathrm{mg}$ patch & $2(3.3)$ \\
\hline RIVASTIGMINE $9.5 \mathrm{mg}$ patch & $17(28.3)$ \\
\hline Included in a clinical trial & $100(51)$ \\
\hline
\end{tabular}

AD, Alzheimer's disease; CMRR, Centres de mémoire, de recherche et de ressources (Centres for Research and Resources on Memory); FCSRT, free and cued selective reminding test; MMSE, mini mental state examination.

Interestingly, and although the mean (SD) MMSE score was $24.7(0.2)$, well above 20, the FCSRT free (10.8 $(0.4))$ and total $(29.1(1.8))$ recall scores indicated a severe amnestic syndrome of the hippocampal type well below the chosen cut-off scores of 20 and 42, respectively. The mean (SD) phosphorylated tau/Aß1-42 ratio of 0.21 (0.01) was also largely above the threshold of 0.11 suggesting an unambiguous $\mathrm{AD}$ pathophysiological process in the participants.

The number of new patients included in the BNA between 2014 and 2018 was 550 198. Among them, 72174 (13\%) were diagnosed with an early AD including MMSE $\geq 20$. These results are presented in tables 2 and 3. Using specificity correction to account for the clinic-pathological accuracy of $\mathrm{AD}$ diagnosis, we estimate that, among the 72174 patients diagnosed with AD between 2014 and 2018, about 50000 had a clinical AD with probable AD brain pathology.

In the $\mathrm{BNA}$, the rate of $\mathrm{CSF}$ biomarker use for $\mathrm{AD}$ diagnosis varied from $2.1 \%$ to $6.7 \%$.

The differences between patients seen in the 11 CMRR who volunteered to participate in the detailed study and the 18 other CMRR are presented in table 4 .

\section{DISCUSSION}

This observational study in a clinical setting on a national scale was specifically designed to estimate the incidence, and describe the characteristics, of patients at early stages of $\mathrm{AD}$ according to recent biomarker-based diagnostic criteria. As evidence suggests that disease-modifying drugs may be efficient at these stages, such an analysis is useful and timely, allowing for the discovery of how many patients can be expected to enrol in trials and in the future to be prescribed such a drug, should one become available. ${ }^{91027}$ This study is different from those conducted in other countries such as in the Netherlands ${ }^{28}$ or in the $\mathrm{USA}^{19}$ in which $\mathrm{AD}$ pathophysiological markers are performed in a research setting. Our main finding is that the incidence of diagnosed $\mathrm{AD}$ at the mild dementia and prodromal stages is lower than previously thought. We also showed that the use of the latest research criteria to diagnose early stage $\mathrm{AD}$ in clinical practice is rare. In France, the latest reports indicate an incidence of up to 225000 new AD cases per year. ${ }^{29}$ This number accounts for all stages of $\mathrm{AD}$ and is an estimation from the general population. This discrepancy between this previous finding of 225000 new $\mathrm{AD}$ cases per year and our result of about 10000 new early AD cases per year can also be explained by several points:

1. Our analysis does not include a significant portion of the clinical setting in which patients with cognitive complaints are evaluated, especially with regards to the non-hospital based or neurologists from private practice. The BNA includes data from only about 90 private specialists, providing data on $2.2 \%$ of the $\mathrm{AD}$ and $2.5 \%$ of the MCI patients in the BNA. As there are about 800 French private neuro specialists, although not all so active in the field of neurodegenerative disorders, one could assume that private specialists consult a large additional number of patients for cognitive problems. However, thanks to a systematically organised medical system with hierarchised and personalised care plan and management (figure 2), our results can be generalised to the French AD medical community. ${ }^{30}$

2. Patients do not consult a specialist when they have MCI or mild dementia. One should note that the databases analysed in our study only represent the patients diagnosed by memory specialists. Our analyses do not account for patients who did not consult any physi- 
Table 2 New patients with Alzheimer's disease in the National Alzheimer Database (BNA) in 2014 and 2015 stratified by MMSE values

\begin{tabular}{|c|c|c|c|c|c|c|c|c|c|}
\hline \multicolumn{2}{|l|}{$\mathbf{N}(\%)$} & \multicolumn{4}{|c|}{$2014(n=119493)$} & \multicolumn{4}{|c|}{$2015(n=113585)$} \\
\hline \multirow{2}{*}{$\begin{array}{l}\text { Clinical } \\
\text { syndrome } \\
A D\end{array}$} & \multirow{2}{*}{$\begin{array}{l}\text { Type of clinic } \\
\text { Primary memory clinic }\end{array}$} & \multicolumn{2}{|c|}{ MMSE <20 } & \multicolumn{2}{|c|}{ MMSE $\geq 20$} & \multicolumn{2}{|c|}{ MMSE <20 } & \multicolumn{2}{|c|}{ MMSE $\geq 20$} \\
\hline & & 10534 & $(60.00)$ & 7018 & $(40.00)$ & 8363 & $(62.00)$ & 5137 & (38.10) \\
\hline & CMRR & 2365 & $(54.80)$ & 1953 & $(45.20)$ & 2073 & $(53.90)$ & 1776 & $(46.10)$ \\
\hline & Private neurologist & 259 & $(45.30)$ & 313 & (54.70) & 176 & $(44.00)$ & 224 & $(56.00)$ \\
\hline & Total AD & 13158 & (53.37) & 9284 & (46.63) & 10612 & $(53.30)$ & 7137 & (46.73) \\
\hline \multirow[t]{4}{*}{$\mathrm{aMCl}$} & Primary memory clinic & 183 & $(6.40)$ & 2668 & $(93.60)$ & 197 & $(6.90)$ & 2669 & (93.10) \\
\hline & CMRR & 47 & $(4.50)$ & 994 & $(95.50)$ & 30 & $(3.30)$ & 889 & (96.70) \\
\hline & Private practice neurologist & 5 & $(2.40)$ & 200 & $(97.60)$ & 3 & $(2.40)$ & 121 & $(97.60)$ \\
\hline & Total aMCl & 235 & $(4.43)$ & 3862 & $(95.57)$ & 230 & $(4.20)$ & 3679 & $(95.80)$ \\
\hline \multirow[t]{4}{*}{ naMCl } & Primary memory clinic & 256 & $(6.30)$ & 3807 & (93.70) & 256 & $(6.90)$ & 3467 & (93.10) \\
\hline & CMRR & 72 & $(4.10)$ & 1669 & (95.90) & 73 & $(4.30)$ & 1612 & (95.70) \\
\hline & Private neurologist & 2 & $(0.90)$ & 225 & (99.10) & 5 & $(3.90)$ & 125 & $(96.20)$ \\
\hline & Total naMCl & 330 & (3.77) & 5701 & (96.23) & 334 & $(5.03)$ & 5204 & $(95.00)$ \\
\hline Grand total & & 13723 & (20.52) & 18847 & (79.48) & 11176 & (20.84) & 16020 & (79.18) \\
\hline
\end{tabular}

$\mathrm{AD}$, Alzheimer's disease; aMCl, amnestic mild cognitive impairment; CMRR, Centres de mémoire, de recherche et de ressources (Centres for Research and Resources on Memory); MMSE, Mini Mental State Evaluation; naMCI, non-amnestic mild cognitive impairment.

cian nor for those who consulted their general practitioner and were not referred to a specialist. It has been shown in the $3 \mathrm{C}$ study ${ }^{31}$ that among the 201 subjects with 'prevalent dementia', $61.4 \%$ consulted a general practitioner for a 'cognitive problem' and $32.9 \%$ consulted a specialist. ${ }^{32}$ After 80 years of age, only $19.7 \%$ of this elderly population did consult a memory specialist. This is also the case in other countries. In Finland, $48.2 \%$ of demented patients in the study by Lopponen et al had previously been diagnosed by a physician. ${ }^{33}$ This percentage decreased to $33 \%$ when the MMSE was $>20$. This underdiagnosis of $\mathrm{AD}$ and dementia has also been found in population studies in Sweden, ${ }^{34}$ Great Britain, ${ }^{35}$ Canada $^{36}$ and the USA. ${ }^{37}$ There are many reasons for the underdiagnosis of dementia, from the slowness of the cognitive changes ${ }^{38}$ to the fearful/fatalistic attitude regarding this irreversible disease. Moreover, general practitioners do not often refer their patients to a neuro specialist as only $41 \%$ of them consider that the specific treatments of $\mathrm{AD}$ are efficient. ${ }^{39}$ These two first points are important to consider as a selection bias. Of course, our data are not representative of the overall French incidence of early stages AD in 2014 and 2015 but only of diagnosed cases, that is, individuals who either by themselves or due to a caregiver or physician came to have a neurological evaluation. No data exist yet in France to address the discrepancy between the total number of early stages $\mathrm{AD}$ and the diagnosed cases. The French cohort CONSTANCES, aiming to recruit 200000 individuals randomly selected from a population and to follow them for 5 years with a yearly cognitive assessment for elderly participants and $\mathrm{AD}$ diagnosis recording will allow researchers to address this critical point. ${ }^{40}$ This contrast between clinical and population-based data will be the subject of further studies.

3. Many patients are already in an advanced dementia stage when they consult for the first time. In the BNA, the mean $( \pm \mathrm{SD})$ MMSE score at the time of AD diagnosis was found to be $18.9( \pm 5.5){ }^{41}$

4. The thresholds chosen to ascertain episodic memory impairment of the hippocampal type or AD CSF profile may be too strict, thus resulting in some false-negative subjects.

5. The decision to exclude 'mixed dementia' patients from our analyses can certainly account for a lower number of $\mathrm{AD}$ patients who may be eligible for a drug trial. This choice was made to be as close as possible to the current trial inclusion criteria although, should one disease-modifying drug become available, the decision to treat these patients or not will have to be made on a case by case basis and foster new trials. As already reported in other studies, focusing on the generalisability of clinical trial criteria in community samples ${ }^{42}$ the stricter the eligibility criteria, the less generalisable the trial is. As it is, this criteria will severely limit the broad application of a disease-modifying treatment, should one become available in the coming years. There is a balance to be found between eligibility criteria that should on one hand yield an optimal internal validity to a trial and on the other hand, would accurately reflect treatment effect in clinical settings. ${ }^{43}$

6. Biomarker data as required by IWG-2 criteria are available in clinical setting to only a minority of patients. In 


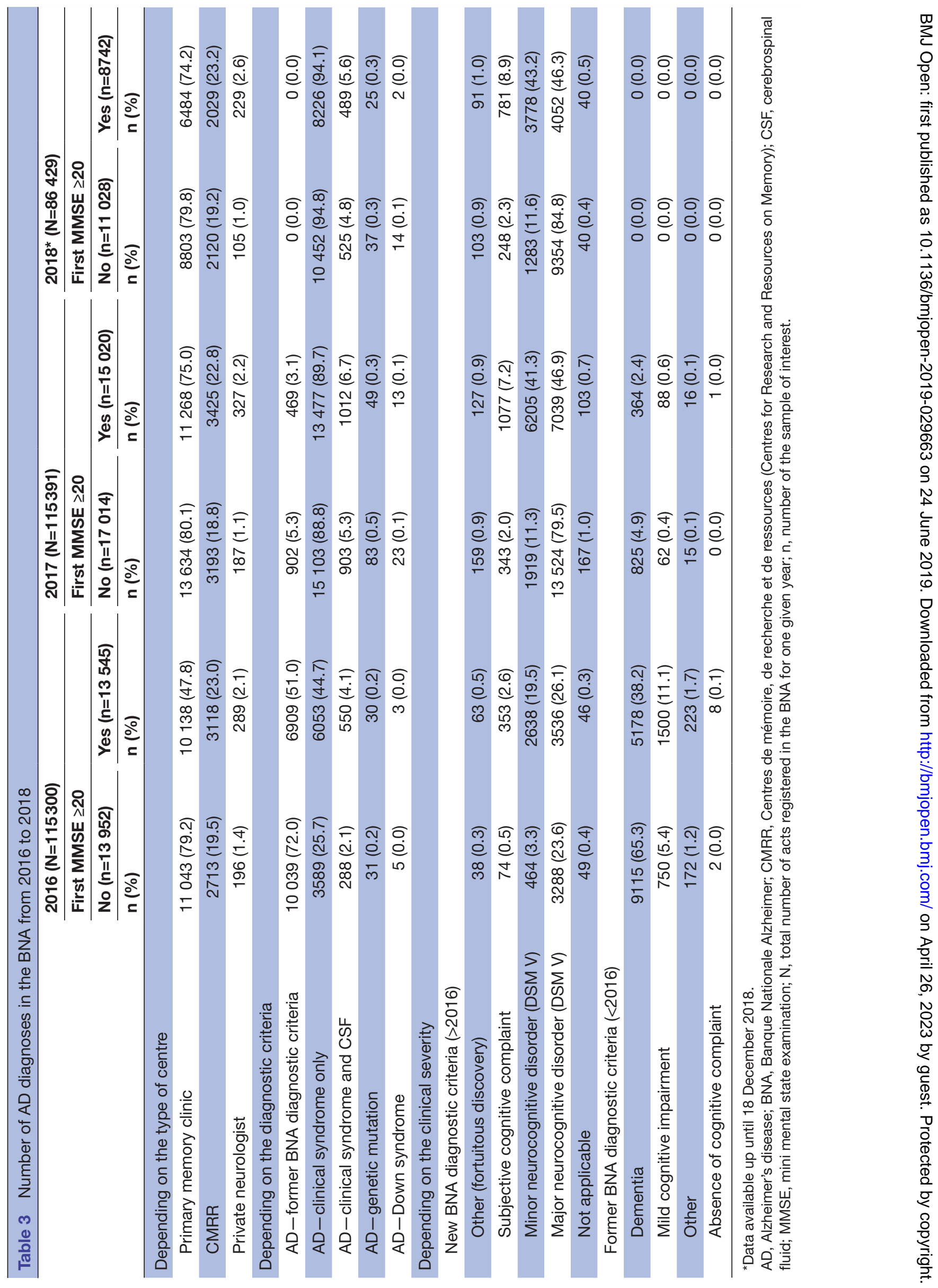


Table 4 Comparison between two groups of patients diagnosed with AD or MCl in the BNA in 2014 either in the 11 CMRRs participating in the detailed analysis (Group 1) or in the 18 other French CMRRs

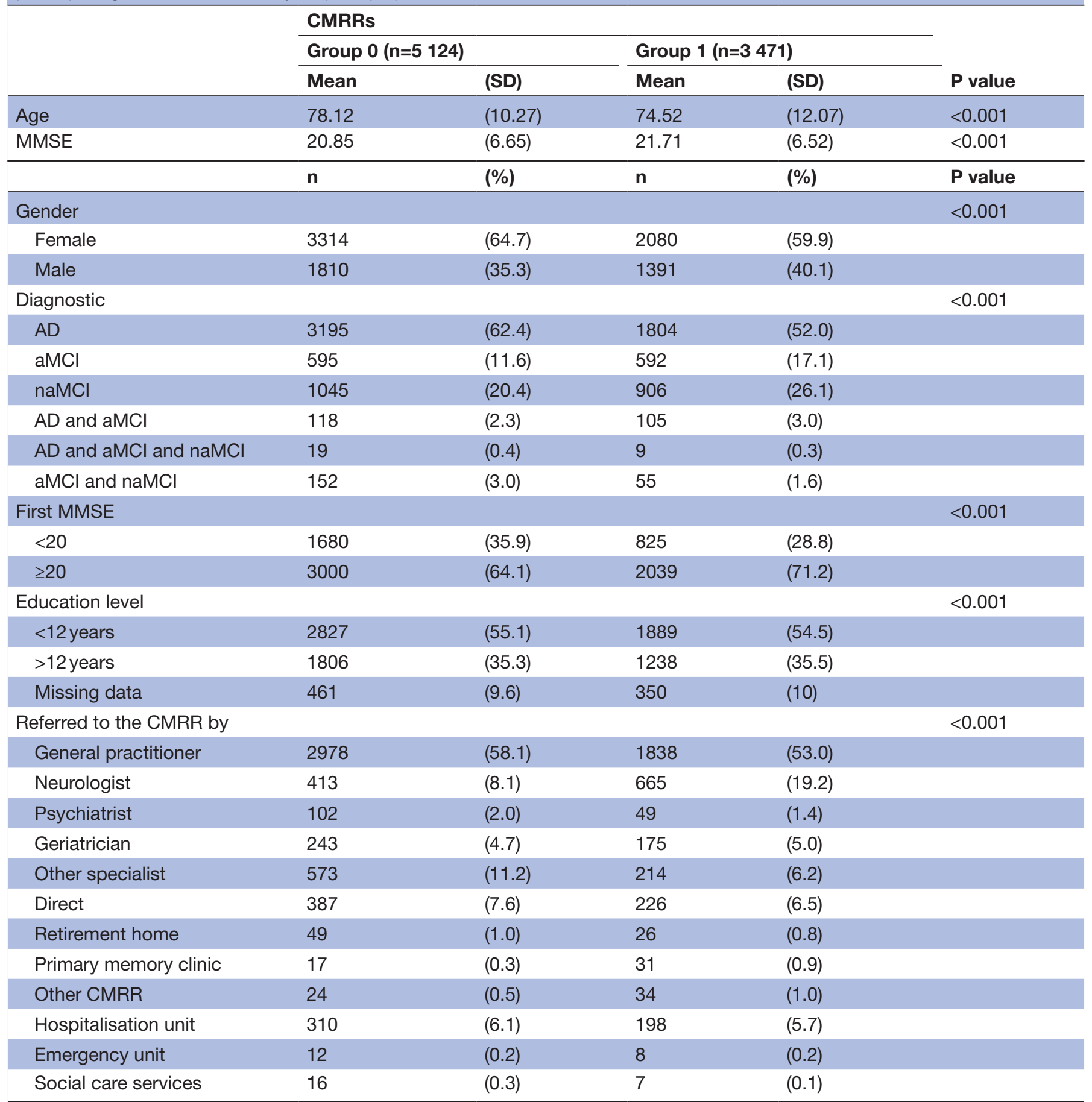

Group 0 (18 CMRR): Bordeaux, Clermont-Ferrand, Caen, Brest, Rennes, Reims, Corse, Besançon, Paris-Broca, Montpellier, Limoges, Toulouse, Marseille, Angers, Amiens, Grenoble, Villeurbanne, Saint-Etienne.

Group 1 (11 CMRR): Dijon, Lille, Nantes, Vandœuvre-Lès-Nancy, Nice, Paris -Lariboisière, Paris-Pitié Salpêtrière, Poitiers, Rouen, Strasbourg, Tours.

AD, Alzheimer's disease; aMCl, amnestic mild cognitive impairment; CMRR, Centre for memory research and resource; MCl, mild cognitive impairment; MMSE, Mini Mental State Evaluation; naMCI, non-amnestic mild cognitive impairment.

the 11 expert centres of our study, we estimate that they were performed in $10 \%$ of the prodromal to mild $\mathrm{AD}$ group. CSF AD biomarker sampling through lumbar puncture, although authorised in the national health guidelines on $\mathrm{AD}$ diagnosis, is not systematically performed on all patients with a possible diagnosis of AD. The actual recommendations from the French health authorities stipulate that these biomarkers are espe- 


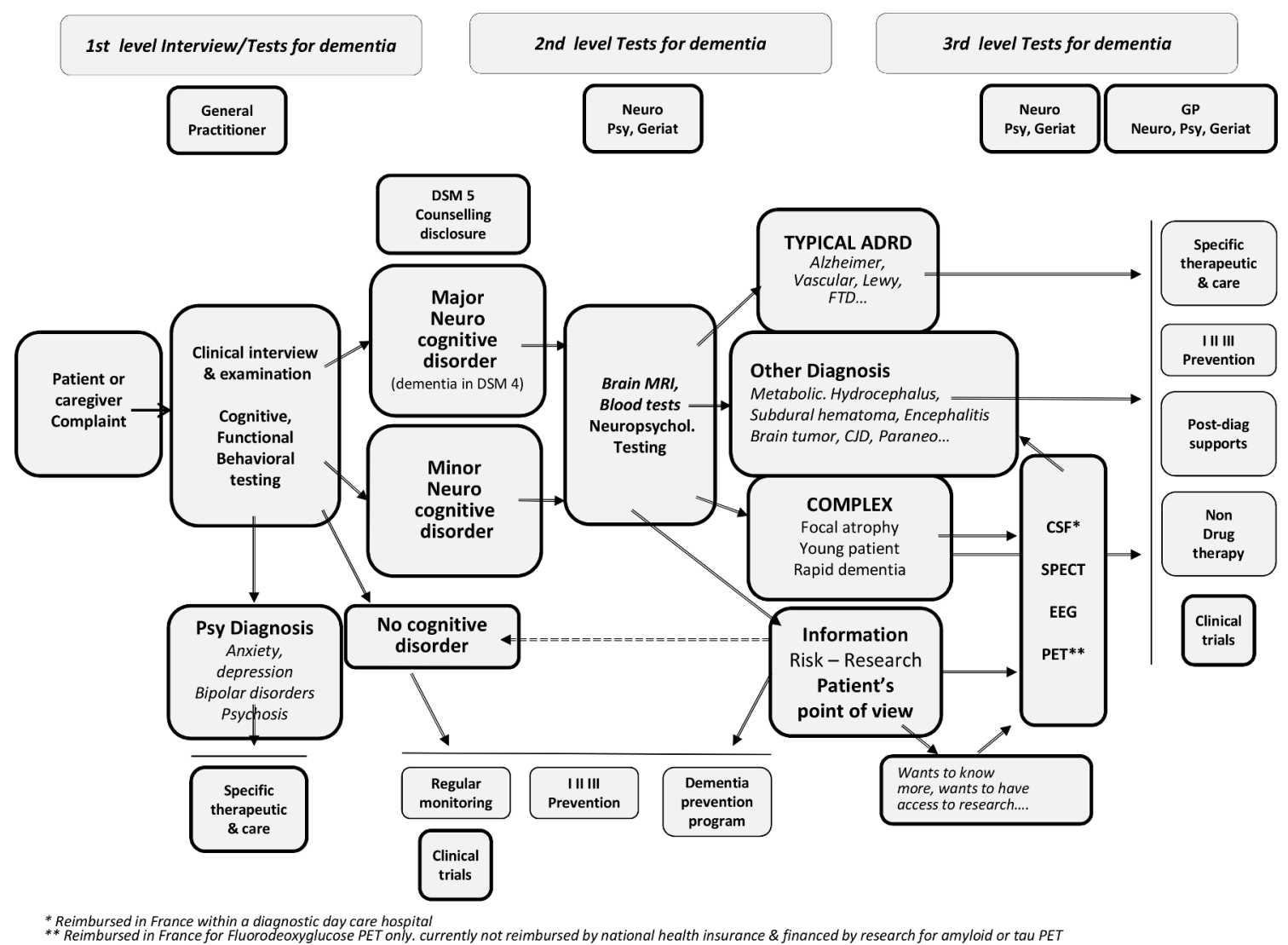

Figure 2 Clinical path of a patient consulting for a cognitive complaint in France. This scheme details the hierarchised and personalised strategy proposed for any given new patient. CJD, Creutzfeldt Jakob disease; CSF, cerebrospinal fluid; DSM, Diagnostic statistical manual; EEG, electroencephalography; FTD, fronto-temporal dementia; Geriat, Geriatrician; GP, General Practitioner; I II III prevention, primary, secondary and tertiary prevention; Neuro, Neurologist; PET, positron emission tomography; Psy, Psychiatrist; SPECT, single photon emission CT.

cially useful in young onset dementia and dementia with an atypical presentation, not in MCI or in patients with a typical clinical AD dementia profile. Indeed, a previous study, also conducted in France, showed that these markers are mainly used in cases of atypical dementia or diagnostic uncertainty. ${ }^{44}$ This explains the relatively young age of the 195 patients (mean: 70.8 year) when compared with a previously published mean age of 80.9 years of all AD patients in the BNA. ${ }^{41}$ Considering our findings, we can argue that CSF biomarkers be used more frequently in expert memory centres as they have been described to provide good accuracy for $\mathrm{AD}$ diagnosis in clinical practice ${ }^{45}$ and influence clinicians in their decision-making processes. ${ }^{46}$ Since March 2016, a new BNA version has been implemented. Clinicians are now asked to answer questions concerning the main syndromic alteration observed (in memory, language, praxis, executive functions, or visuospatial ability), the stage of the patient (whether they have a subjective complaint, MCI or a major cognitive disorder) and the probable aetiology of the cognitive impairment. They are also asked if $\mathrm{AD}$ aetiology is supported by a biomarker measurement or not. This new paradigm will allow for a finer delineation of the epidemiology of early stage $\mathrm{AD}$ and will be the focus of future studies. We focused on cognitive and CSF markers of AD in this study and not on amyloid or fluorodeoxyglucose (FDG) positron emission tomography (PET) or MRI because of two main reasons. First, amyloid PET is not routinely available in French clinics, whereas CSF biomarkers are. Second, MRI and FDG PET are topographic markers with lower specificity than CSF biomarkers. The choice of the association of cognition and CSF markers to ascertain the diagnosis of $\mathrm{AD}$ is consistent with the IWG-2 criteria. This is also in line with the recently revised NIA AA criteria based on Jack et al. A/T/N classification which states that MRI and FDG PET can be used to diagnose 'neurodegeneration' considered not specific to $\mathrm{AD} .{ }^{4748}$

7. Finally, a worldwide decrease in the incidence of $\mathrm{AD}$ has been described in a number of independent studies, ${ }^{49-51}$ possibly linked to an improvement of the general health risk factors and a higher education level in the countries from which these cohorts derive. Nevertheless, this element most probably could only explain a small part of the discrepancy.

In a post-hoc survey conducted in the 11 participating CMRRs, the main reasons mentioned to explain the small number of identified patients eligible for a disease-modifying drug trial were the absence of referral of $\mathrm{AD}$ 
patients at an early stage of the disease, the fact that the lumbar puncture is not recommended in typical amnestic $\mathrm{AD}$ unless it occurs before 65 years of age, and the fact that some patients could have $\mathrm{AD}$ and not be within the chosen cognitive thresholds for this study.

Interestingly, the 195 patients identified with prodromal or mild $\mathrm{AD}$ in the 11 CMRRs, which are part of the third-line healthcare organisation, had been most often referred by their general practitioners, whereas one would expect they would be referred mainly by neuro specialists in the second line. This lack of 'specialised referral' is also supported by the small geographical distance $(40.1 \pm 6.7 \mathrm{~km})$ separating these patients from the CMRR.

This study has limitations including its retrospective design for the electronic record file database that does not allow us to draw definitive epidemiological conclusions, but still raises the level of awareness concerning the relatively low diagnostic rate of $\mathrm{AD}$ at its early clinical stage.

Another limitation is that our study, so far and to our knowledge, cannot be generalised to other countries because we lack recent epidemiological data on $\mathrm{AD}$ on the same scale as our study. Results from these studies ${ }^{52}$ are usually derived from cohorts recruited in the 1990s or 2000s and not these last years. This fact alone is troublesome both because of the suggested trend in $\mathrm{AD}$ incidence decrease in these last decades ${ }^{50} 51$ and because the recruitment in these cohorts predates the newest diagnostic criteria for $\mathrm{AD} .{ }^{3515}$ Finally, early $\mathrm{AD}$ is never individualised in these studies focusing on $\mathrm{AD}$ whatever the severity at diagnosis. Also, the use of biomarkers is never disclosed in these epidemiological studies.

\section{CONCLUSIONS}

Our study is the first and largest to address the critical question of the frequency of a specific $\mathrm{AD}$ diagnosis at its early stages in clinical routine. Our estimations of the incidence of clinically diagnosed prodromal or mild AD are only a fraction of previous incidence estimations of $\mathrm{AD}$ in the general population. ${ }^{29}$ This finding, which is based on two different database analyses, is generalisable on a national scale due to the large number of included participants and the 5-year period of evaluation. Similar findings will have to be evidenced in other countries to be able to generalise these results on a global scale. This topic is important to consider since new disease-modifying drugs, specifically designed to target this population of patients, may become available in the coming years. If the ongoing trials yield positive results, we will be confronted with an unprecedented 'rush towards treatment' from a huge number of patients. These treatments should, however, only be proposed to patients if there is potential expected efficacy. Thus, the selection of patients, fitting the successful trial's inclusion criteria, should be identified by expert centres. Also, new diagnostic tests such as amyloid PET, which has recently been proved to change the care and management plan in $>60 \%$ of patients with MCI or dementia ${ }^{53}$ or amyloid sampling in blood, ${ }^{54}$ may transform the diagnostic procedures of patients with cognitive complaints or impairments in the near future. Large efforts will have to be made in order to improve the diagnostic procedures, and access to these procedures, for patients at an early stage of AD. National databases are valuable tools to monitor these diagnostic procedures and improve them.

\section{Author affiliations}

${ }^{1}$ Institute of Memoryand Alzheimer's Disease (IM2A) and Brain and Spine Institute(ICM) UMR S 1127, Inria, Aramis-Project Team, Department of Neurology, AP-HP, Pitié-Salpêtrière University Hospital, Sorbonne Universities, Pierre et Marie Curie University, Paris 06 and National Reference Center for Rare or Early Dementias and Center of Excellence of Neurodegenerative Disease (CoEN), Paris, France

${ }^{2}$ Neurology Memory Center, Lariboisière FW Saint Louis University Hospital, Paris, France

${ }^{3}$ Center of Cognitive Neurology, Groupe hospitalier Lariboisiere Fernand-Widal, Paris, France

${ }^{4}$ Cognitive Neurology Center, CMRR Paris-Nord Ile-de-France, Groupe hospitalier Lariboisiere Fernand-Widal, Paris, France

${ }^{5}$ U942 Team Biomarkers and Neurocognition, INSERM/Université Paris Diderot, Paris, France

${ }^{6}$ Department of Neurology, Rouen University Hospital, Rouen, France

${ }^{7}$ Department of Neurology, CHU Charles Nicolle, Rouen, France

${ }^{8}$ Gériatrie, CHRU de Nancy, Nancy, France

${ }^{9}$ Gériatrie, CHU de Tours, Tours, France

${ }^{10}$ Department of Neurology, University Hospital of Strasbourg, Strasbourg, France

${ }^{11}$ Gériatrie, CHU de Strasbourg, Strasbourg, France

${ }^{12}$ Gériatrie, CHU de Poitiers, Poitiers, France

${ }^{13}$ Geriatrics Department University Hospital La Milétrie, Poitiers, France

${ }^{14}$ Neurology, Centre Hospitalier Regional et Universitaire de Lille (CHRU- LILLE), Lille, France

${ }^{15}$ Neurology, Centre Hospitalier Regional Universitaire de Lille Pole Neurosciences et Appareil Locomoteur, Lille, France

${ }^{16} \mathrm{CHU}$ Nantes, Nantes, France

${ }^{17}$ Neurology, CHU de Nantes, Nantes, France

${ }^{18}$ Neurology, CHU de Dijon, Dijon, France

${ }^{19}$ Department of Neuropsychiatry, CHU de nice, Nice, France

${ }^{20}$ Centre Mémoire de Ressources et de Recherche, Centre Hospitalier Universitaire de Nice, Nice, France

${ }^{21}$ Department of Clinical Research, Institut du cerveau et de la moelle epiniere,

Paris, France

${ }^{22}$ Délégation à la Recherche Clinique et à I'Innovation, Assistance publiqueHôpitaux de Paris, Paris, France

${ }^{23}$ Medical Department, Eli Lilly and Co, Indianapolis, Indiana, USA

${ }^{24}$ Neurology, CHU de la Pitiè Salpêtrière-AP-HP, Paris, France

Acknowledgements The authors thank Tim Daly for proofreading the manuscript. Contributors SE, CP, JH, JD, DW, DH, TJ, AB, SP, CH, FB, LB, AJ, MP, FP, JB, $\mathrm{CB}, \mathrm{TC}, \mathrm{OR}, \mathrm{OM}, \mathrm{AM}, \mathrm{RD}, \mathrm{SB}$ and $\mathrm{RF}$ contributed to data acquisition and writing of the manuscript (critical comments). EL helped in the coordination of the 11 participating centres. WD helped in the interpretation of the results and in writing of the manuscript (critical comments). SE conceived the study, analysed the data and wrote the initial draft of the manuscript. RF participated in the data analysis. PR and BD supervised the study.

Funding The funding of this study was supported by Eli Lilly. Dr S Epelbaum and Professor B Dubois received honoraria as consultant and/or speaker on behalf of El Lilly. Eli Lilly's sponsoring of the study served to build and monitor the unified ECR database. Furthermore, WD from Eli Lilly helped in the interpretation of the results and revising the manuscript.

Competing interests None declared.

Patient consent for publication Not required. 
Ethics approval Both the ECR and BNA databases and their utilisation for the purpose of this study were approved by Paris VI Institutional Review Board and the Commission Nationale de l'Informatique et des Libertés (CNIL) responsible in France for data protection and use regarding human identity and human rights.

Provenance and peer review Not commissioned; externally peer reviewed.

Data sharing statement The BNA data are available through the BNA website (http://www.innovation-alzheimer.fr/bna-fr/). It is required to contact the scientific committee of the BNA to gain access to the data.

Open access This is an open access article distributed in accordance with the Creative Commons Attribution Non Commercial (CC BY-NC 4.0) license, which permits others to distribute, remix, adapt, build upon this work non-commercially, and license their derivative works on different terms, provided the original work is properly cited, appropriate credit is given, any changes made indicated, and the use is non-commercial. See: http://creativecommons.org/licenses/by-nc/4.0/.

\section{REFERENCES}

1. Brookmeyer R, Evans DA, Hebert L, et al. National estimates of the prevalence of Alzheimer's disease in the United States. Alzheimers Dement 2011;7:61-73.

2. Cummings J, Lee G, Mortsdorf T, et al. Alzheimer's disease drug development pipeline: 2017. Alzheimers Dement 2017;3:367-84.

3. Albert MS, DeKosky ST, Dickson D, et al. The diagnosis of mild cognitive impairment due to Alzheimer's disease: recommendations from the National Institute on Aging-Alzheimer's Association workgroups on diagnostic guidelines for Alzheimer's disease. Alzheimers Dement 2011;7:270-9.

4. Dubois B, Feldman $\mathrm{HH}$, Jacova $\mathrm{C}$, et al. Research criteria for the diagnosis of Alzheimer's disease: revising the NINCDS-ADRDA criteria. Lancet Neurol 2007;6:734-46.

5. Dubois B, Feldman $\mathrm{HH}$, Jacova $\mathrm{C}$, et al. Advancing research diagnostic criteria for Alzheimer's disease: the IWG-2 criteria. Lancet Neurol 2014;13:614-29.

6. Tapiola T, Alafuzoff I, Herukka SK, et al. Cerebrospinal fluid \{beta\}amyloid 42 and tau proteins as biomarkers of Alzheimer-type pathologic changes in the brain. Arch Neurol 2009;66:382-9.

7. Honig LS. EXPEDITION 3: A phase 3 Trial of Solanezumab in Mild Dementia due to Alzheimer's Disease. San Diego: CTAD, 2016.

8. Eisele P, McConnell I, Loxam T, et al. Merck Announces EPOCH Study of Verubecestat for the Treatment of People with Mild to Moderate Alzheimer's Disease to Stop for Lack of Efficacy. MSD, ed. Kenilworth, N.J., U.S.A, 2017

9. Sevigny J, Chiao P, Bussière T, et al. The antibody aducanumab reduces $A \beta$ plaques in Alzheimer's disease. Nature 2016;537:50-6.

10. Eisai. Eisai and Biogen announce positive topline results of the final analysis for BAN2401 at 18 months. enews201858. 2018.

11. Le Duff F, Develay AE, Quetel J, et al. The 2008-2012 French Alzheimer plan: description of the national Alzheimer information system. J Alzheimers Dis 2012;29:891-902.

12. Tay L, Lim WS, Chan M, et al. New DSM-V neurocognitive disorders criteria and their impact on diagnostic classifications of mild cognitive impairment and dementia in a memory clinic setting. Am J Geriatr Psychiatry 2015;23:768-79.

13. Folstein MF, Folstein SE, McHugh PR. "Mini-mental state". A practical method for grading the cognitive state of patients for the clinician. J Psychiatr Res 1975;12:189-98.

14. WHO. International Classification of Diseases.

15. McKhann GM, Knopman DS, Chertkow H, et al. The diagnosis of dementia due to Alzheimer's disease: recommendations from the National Institute on Aging-Alzheimer's Association workgroups on diagnostic guidelines for Alzheimer's disease. Alzheimers Dement 2011;7:263-9.

16. Petersen RC. Mild cognitive impairment as a diagnostic entity. J Intern Med 2004;256:183-94.

17. Beach TG, Monsell SE, Phillips LE, et al. Accuracy of the clinical diagnosis of Alzheimer disease at National Institute on Aging Alzheimer Disease Centers, 2005-2010. J Neuropathol Exp Neurol 2012;71:266-73.

18. Salloway S, Sperling R, Fox NC, et al. Two phase 3 trials of bapineuzumab in mild-to-moderate Alzheimer's disease. $N$ Engl J Med 2014;370:322-33.

19. Petersen RC, Aisen P, Boeve BF, et al. Mild cognitive impairment due to Alzheimer disease in the community. Ann Neurol 2013;74:199-208.

20. Grober E, Buschke H, Crystal H, et al. Screening for dementia by memory testing. Neurology 1988;38:900-3.
21. Di Stefano F, Epelbaum S, Coley N, et al. Prediction of Alzheimer's Disease Dementia: Data from the GuidAge Prevention Trial. $J$ Alzheimers Dis 2015;48:793-804.

22. Sarazin M, Berr C, De Rotrou J, et al. Amnestic syndrome of the medial temporal type identifies prodromal AD: a longitudinal study. Neurology 2007;69:1859-67.

23. Auriacombe $\mathrm{S}$, Helmer $\mathrm{C}$, Amieva $\mathrm{H}$, et al. Validity of the free and cued selective reminding test in predicting dementia: the $3 \mathrm{C}$ study. Neurology 2010;74:1760-7.

24. Grober E, Hall C, Sanders AE, et al. Free and cued selective reminding distinguishes Alzheimer's disease from vascular dementia. $J$ Am Geriatr Soc 2008:56:944-6.

25. Grober E, Sanders AE, Hall C, et al. Free and cued selective reminding identifies very mild dementia in primary care. Alzheimer Dis Assoc Disord 2010;24:1-90.

26. Duits $\mathrm{FH}$, Teunissen $\mathrm{CE}$, Bouwman $\mathrm{FH}$, et al. The cerebrospinal fluid "Alzheimer profile": Easily said. but what does it mean? Alzheimers Dement 2014.

27. Ostrowitzki S, Deptula D, Thurfjell L, et al. Mechanism of amyloid removal in patients with Alzheimer disease treated with gantenerumab. Arch Neurol 2012;69:198-207.

28. van der Flier WM, Pijnenburg YA, Prins N, et al. Optimizing patient care and research: the Amsterdam Dementia Cohort. $J$ Alzheimers Dis 2014;41:313-27.

29. Commenges D, Joly $P$, Letenneur L, et al. Incidence and mortality of Alzheimer's disease or dementia using an illness-death model. Stat Med 2004;23:199-210.

30. Krolak-Salmon P, Letrilliart L, Ceccaldi M, et al. [Towards a national strategy on the diagnosis of neurocognitive disorders. A shared approach among the French National College of General Practitioners and specialists of neurocognitive disorders]. Presse Med 2018;47:75-83.

31. Alpérovitch A, Amouyel P, Dartigues JF, et al. [Epidemiological studies on aging in France: from the PAQUID study to the Three-City study]. C R Biol 2002;325:665-72.

32. Amieva $\mathrm{H}$, Andrieu $\mathrm{S}$, Berr $\mathrm{C}$, et al. Accès au diagnostic et parcours de soins. In: centre Ice, ed. Maladie d'Alzheimer enjeux scientifiques, médicaux et sociétaux. Paris: Inserm publication, 2007:431-45.

33. Löppönen M, Räihä I, Isoaho R, et al. Diagnosing cognitive impairment and dementia in primary health care - a more active approach is needed. Age Ageing 2003;32:606-12.

34. Olafsdóttir M, Skoog I, Marcusson J. Detection of dementia in primary care: the Linköping study. Dement Geriatr Cogn Disord 2000;11:223-9.

35. O'Connor DW, Pollitt PA, Hyde JB, et al. Do general practitioners miss dementia in elderly patients? BMJ 1988;297:1107-10.

36. Bush C, Kozak J, Elmslie T. Screening for cognitive impairment in the elderly. Can Fam Physician 1997;43:1763-8.

37. Callahan CM, Hendrie HC, Tierney WM. Documentation and evaluation of cognitive impairment in elderly primary care patients. Ann Intern Med 1995;122:422-9.

38. Rimmer E, Wojciechowska M, Stave C, et al. Implications of the Facing Dementia Survey for the general population, patients and caregivers across Europe. Int J Clin Pract Suppl 2005;146:17-24.

39. Wilkinson D, Sganga A, Stave C, et al. Implications of the Facing Dementia Survey for health care professionals across Europe. Int $J$ Clin Pract 2005;59:27-31.

40. Zins M, Goldberg M. CONSTANCES team. The French CONSTANCES population-based cohort: design, inclusion and follow-up. Eur J Epidemiol 2015;30:1317-28.

41. Pradier C, Sakarovitch C, Le Duff F, et al. The mini mental state examination at the time of Alzheimer's disease and related disorders diagnosis, according to age, education, gender and place of residence: a cross-sectional study among the French National Alzheimer database. PLoS One 2014;9:e103630.

42. Hoertel N, Le Strat $Y$, De Maricourt P, et al. Are subjects in treatment trials of panic disorder representative of patients in routine clinical practice? Results from a national sample. J Affect Disord 2013;146:383-9.

43. Kim ES, Atlas J, Ison G, et al. Transforming Clinical Trial Eligibility Criteria to Reflect Practical Clinical Application. Am Soc Clin Oncol Educ Book 2016;35:83-90.

44. Troussière AC, Wallon $\mathrm{D}$, Mouton-Liger $\mathrm{F}$, et al. Who needs cerebrospinal biomarkers? A national survey in clinical practice. $J$ Alzheimers Dis 2014;40:857-61.

45. Dumurgier J, Vercruysse O, Paquet C, et al. Intersite variability of CSF Alzheimer's disease biomarkers in clinical setting. Alzheimers Dement 2013;9:406-13.

46. Mouton-Liger F, Wallon D, Troussière AC, et al. Impact of cerebrospinal fluid biomarkers of Alzheimer's disease in clinical practice: a multicentric study. J Neurol 2014;261:144-51. 
47. Jack CR, Bennett DA, Blennow K, et al. NIA-AA Research Framework: Toward a biological definition of Alzheimer's disease. Alzheimers Dement 2018;14:535-62.

48. Jack CR, Bennett DA, Blennow K, et al. A/T/N: An unbiased descriptive classification scheme for Alzheimer disease biomarkers. Neurology 2016;87:539-47.

49. Christensen K, Thinggaard M, Oksuzyan A, et al. Physical and cognitive functioning of people older than 90 years: a comparison of two Danish cohorts born 10 years apart. Lancet 2013;382:1507-13.

50. Langa KM, Larson EB, Crimmins EM, et al. A Comparison of the Prevalence of Dementia in the United States in 2000 and 2012. JAMA internal medicine 2016.

51. Matthews FE, Arthur A, Barnes LE, et al. A two-decade comparison of prevalence of dementia in individuals aged 65 years and older from three geographical areas of England: results of the Cognitive Function and Ageing Study I and II. Lancet 2013;382:1405-12.

52. Takizawa C, Thompson PL, van Walsem A, et al. Epidemiological and economic burden of Alzheimer's disease: a systematic literature review of data across Europe and the United States of America. $J$ Alzheimers Dis 2015:43:1271-84.

53. Rabinovici GD, Gatsonis C, Apgar C, et al. Association of Amyloid Positron Emission Tomography With Subsequent Change in Clinical Management Among Medicare Beneficiaries With Mild Cognitive Impairment or Dementia. JAMA 2019;321:1286-94.

54. Nakamura A, Kaneko N, Villemagne VL, et al. High performance plasma amyloid- $\beta$ biomarkers for Alzheimer's disease. Nature 2018;554:249-54. 